\title{
Integrative approach for wastewater treatment facilities with biomass transformation into energy
}

\author{
Yaakov Anker ${ }^{1,2,3,}$, David Mualem ${ }^{1,3}$, Hagai Langstadter ${ }^{3}$, Faina Nakonechny $^{2}$, and Marina Nisnevitch ${ }^{3}$ \\ ${ }^{1}$ Eastern Israel Regional R\&D Center, Ariel University 10, Ariel, Israel \\ 2 The Department of Chemical Engineering (Biotechnology and Materials), Ariel University 4, Ariel, Israel \\ 3 yAlgae Ltd., Tirat HaCarmel, Israel
}

Received: 26 February 2017 / Received in final form: 2 July 2017 / Accepted: 27 July 2017

\begin{abstract}
Current industrial environmental regulations favor processes with Integrative Pollution Prevention and Control (IPPC). While several systems are regarded by different international directives as IPPC Best Available Techniques or Technologies (BAT), none of these systems are capable handling various pollutants of both gaseous and aquatic effluents. Additional hinder to a BAT-IPPC complete procedure are hazardous or uneconomical byproducts of the IPPC processes and significant auxiliary costs for consumables and energy. The current research and subsequent projects are aimed to the development of a Biological Integrative Pollution Prevention and Control (Bio-IPPC) system. Such system can be incorporated in various industrial processes, in a way that the byproduct is without hazardous potential and may be used as an economical raw material. The main initiative and heart of these systems is a micro-algae reactor, which is capable of treating various types of industrial pollutants both in the gaseous and aquatic phases. The algae nutrition is through thin-film circulation of the aquatic effluent and the reactor atmosphere is enriched by flue gases. The excessive algal biomass may be utilized for economic purposes starting with animal feedstock, through organic fertilizer and as industrial raw material for biofuels production or direct energy production. The first industrial project is a wastewater (WW) polishing stage to an industry zone WW treatment facility, which ensures high level effluent purification and assimilation of greenhouse gases, which are released during the WW bioremediation process. The second industrial application aims to treat aquatic and gaseous effluents from coal propelled power plants. The raw algal material from both projects although very different, is used for the development of new efficient scheme for bioethanol production. In summary, the system presented is an actual Bio-IPPC that can interactively treat several industrial effluents, while utilizing the algal biomass as a profitable raw material.
\end{abstract}

\section{Introduction}

While in the previous decade it was estimated that liquid fossil fuels will runout by the end of the new millennia's first century [1,2], regulation in fossil resources production and new prospection and production methodologies indicates that fossil fuels will exist, together with other energy resources for generations to come [3]. Nonetheless, biomass conversion into liquid biofuels such as, bioethanol and biodiesel is a major infrastructure development goal in order to facilitate the reduction in fossil fuel production [4]. Although the "Big" renewable energy potential are probably wind and solar [5], biomass based energy is still considered vital for transportation infrastructure. Transformation of biomass into liquid or gas fuels is already parallel to fossil resources, when biodiesel and bioethanol

\footnotetext{
* e-mail: kobia@ariel.ac.il
}

are vastly used as transportation biofuels. Biodiesel can be derived from microalgae oil or directly from microalgae biomass whereas bioethanol can be produced from microalgae carbohydrate, i.e. microalgal biomass can be fully exploited by conversion of lipids to biodiesel and of residues biomass (carbohydrates) to bioethanol [6].

Since the choice of first-generation biofuel production crop-based feedstock, is either directly or indirectly compete with food crops for very limited arable land resources, second and third generation biofuel feed stocks must be developed to allow the expansion of sustainable biofuel production [7]. Nevertheless, out of all possible utilities of algal biomass, fuel feedstock possesses shows the lowest revenue (Fig. 1) and usually has no economic feasibility [6]. The strategy enrolled in the current paper suggests to integrate the biomass cultivation system as a stage in an integrated waste treatment, known as Integrative Pollution Prevention and Control system (IPPC). IPPC is the current trend in treatment of mostly 


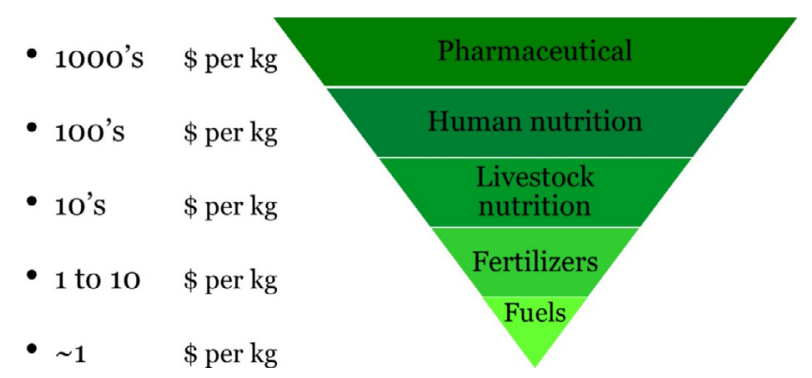

Fig. 1. Biomass revenue scales for different groups of products.

industrial effluents [8,9], when once withstanding in these regulation the system may be defined as Best Available Techniques/Technologies (BAT-IPPC) [10].

While, biomass decomposition either in wastewater (WW) or surplus organic materials releases greenhouse gases (GHG), biomass processing can improve waste treatment processes and resolve such environmental hinders. This new strategy for the application of a Biological Integrative Pollution Prevention and Control system (Bio-IPPC) considers that nutrients and of organic matter in WW may be utilized as feedstock for aquatic biomass cultivation and the carbon dioxide produced in the bacterial stages of a treatment process may improve the vegetal biomass growth rate. Algae for instance thrive in WW Treatment Plants (WWTP) and owing to their fastgrowing biomass and nature are very attractive feedstocks for biofuel production [6]. The integration of algae stage in bacterial WW treatment has additional benefits as they are a complementary system, which backs up the bacterial treatment system and they also assimilate GHG.

Moreover, since in most conventional systems the biomass is grown submersed in aquatic solution the reactors actual surface is limited and biomass cultivation does not exceed productivity of about $0.45 \mathrm{~g} \mathrm{~L} /$ day [11]. The productivity of an activated algae greenhouse with thin-film cultivation methodology, which is imbedded in a WW treatment process, can be higher by order of magnitude and even more (compared to raceway system). In addition to algae, free-floating aquatic plants, such as water hyacinth (Eichhornia crassipes), which is one of the most proliferating and the most productive vegetative species in the world; can also be cultivated in WW basins and aeration pools and may serve as a source of lignocellulosic biomass for bioethanol production. Whereas, in for both feedstocks the development of efficient method for biomass transformation in to biofuels, may improve the economical revenue from algal biomass cultivation as well as assist in mitigation of invasive species such as the water hyacinth.

\section{Methodology}

The main element described in the paper is a Bio-IPPC system where microalgae grown over sub-vertical media, assimilates hazardous elements from aquatic solutions and GHG emission gases. The transformation of the aqueous and gaseous effluent into algal biomass reduces chemical and organic loads and the phase transition from oxygenized

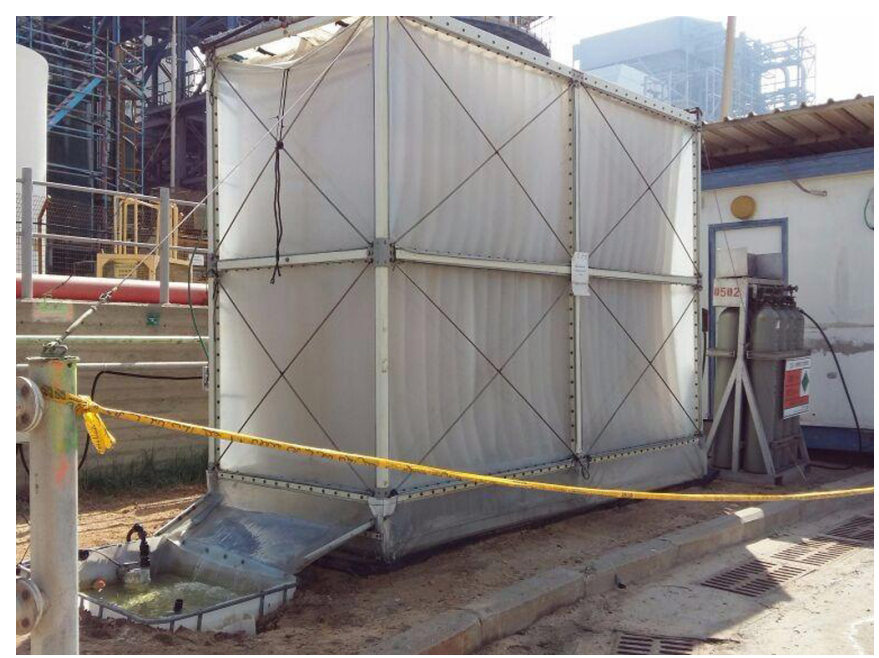

Fig. 2. Picture of the PBR at the Rothenberg coal propelled power station, aimed for reduction in nitrogen compounds and metals in the aquatic solution and for GHGs reduction from the flue gas phase.

through anaerobic to a photosynthetic highly oxygenized phase is also acting as an efficient disinfector. This PhotoBio Reactor (PBR) may replace conventional WW stages; improving the WWTP energy consumption by allowing operation with low oxygen concentration in the aerobic reactor, as residual oxidization will be gained in the PBR.

Moreover, trade tariffs for carbon dioxide and other GHG reduction [12] in the PBR may farther improve the WWTP economic balance. This activated, monitored and controlled aquatic biomass cultivation greenhouse (Fig. 2) is equipped with a conveyer type, continuous algae harvester, which resolved the biomass harvesting challenge [13]. The system is an auxiliary sage for WWTPs [14] and the biomass produced may be processed into biofuels through a new process involving a mechanochemical stage, which enables direct fermentation of algal and water plants biomasses into bioethanol. This new process may improve the current bioethanol and biodiesel production multistage processes by replacing costly aggressive chemicals [15].

\section{Results and discussion}

The first prototype (Ariel West) treated about $10 \mathrm{~m}^{3}$ of industrial effluent per day, reducing its organic load from about $10 \mathrm{mg} / \mathrm{L}$ (Biological Oxygen Demand) to less than $5 \mathrm{mg} / \mathrm{L}$, producing wet algae yield of about $10 \mathrm{~kg}$ per day ( $\sim \mathrm{g} \mathrm{L} /$ day); since the system was embedded to the end of the treatment process it is suggested that once received WW with higher organic and nutrients loads, the biomass productivity would increase. Microalgae grown as part of WWTP systems usually contain lipids in the range of 20 $40 \%$, although in few tests the lipids content was much higher (Fig. 3). This suggests that the system produces biomass feedstock suitable for transformation to biodiesel as well as bioethanol. The microalgae and cyanobacteria species a naturally grown in WW were Nitzschia palea and Scenedesmus sp. or Nostoc, in the low salinity [Total 
6

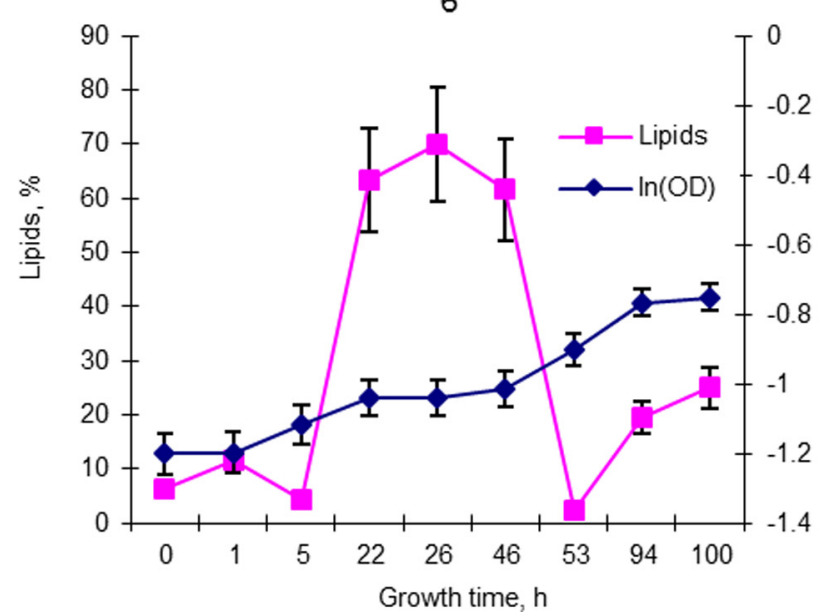

3

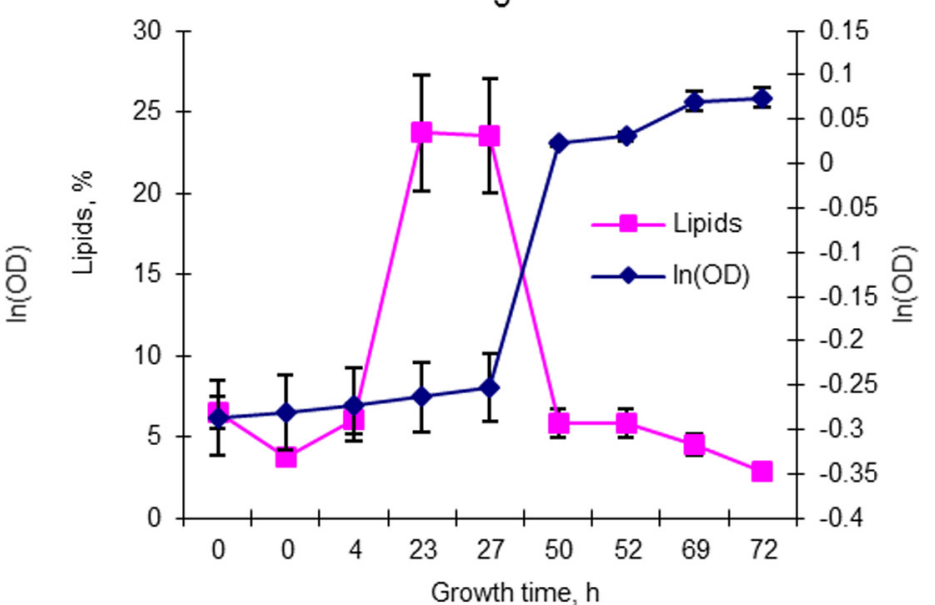

Fig. 3. Monitoring of lipid content in and biomass density in two representative experiments, aimed to define the best combination of growth cycle time and reactor conditions [16].

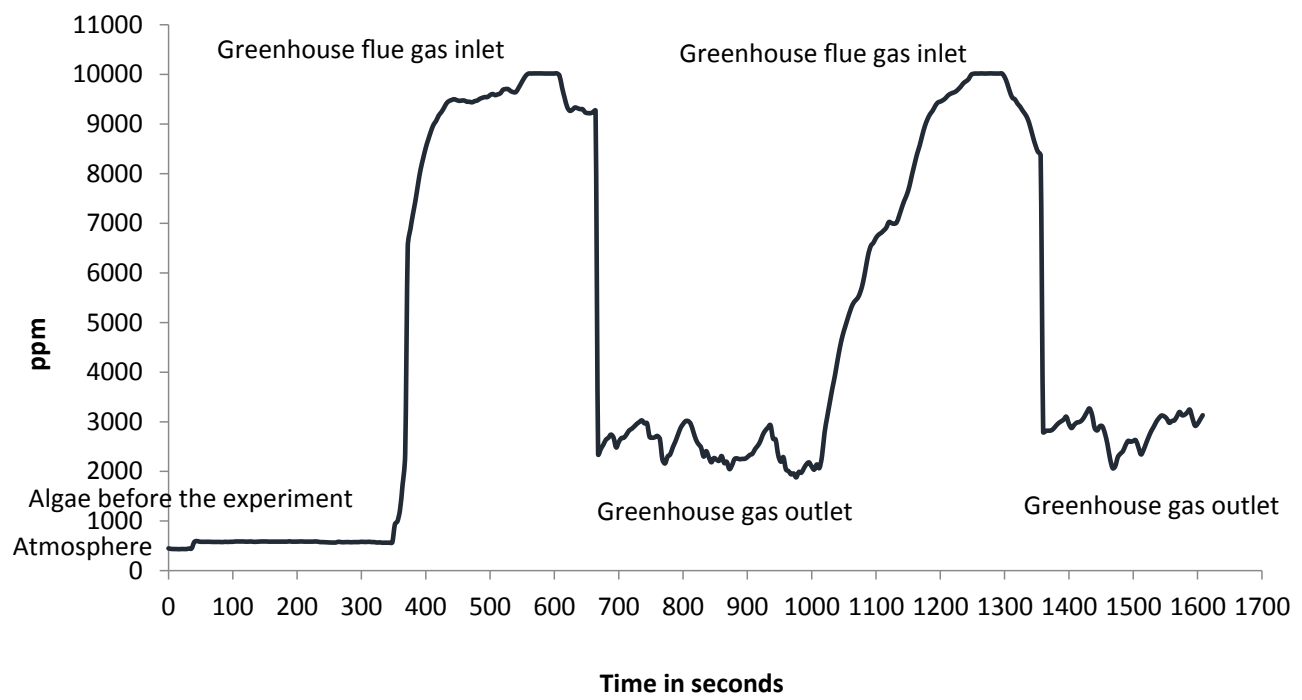

Fig. 4. $\mathrm{CO}_{2}$ concentration monitoring throughout a GHG assimilation experiment preformed during the 22 April 2014 , at the Ariel West research site.

Dissolved Salts (TDS) of 400-700 mg/L] WW of the Ariel West WWTP and Synechocystis salina at the high salinity (TDS above $10000 \mathrm{mg} / \mathrm{L}$ ) Rothenberg power station. The local artificial cultivation system habitat, demonstrated a symbiotic stable condition, adapted to the WW chemical and biological composition. Moreover, it was shown that microalgae depressed coliforms development and caused a significant decrease in their concentration. This approach provides a stable microalgae consortium without the need for sterile conditions.

In series of laboratory tests, spontaneously colonized microalgae from the WWTP were grown in batch, semibatch and continuous regimes, in various temperatures (10$26{ }^{\circ} \mathrm{C}$ ), illuminations and aeration conditions and also with or without $\mathrm{CO}_{2}$ supplementation. Microalgae growth was monitored by measurements of turbidity, wet and dry cells weight, chemical oxygen demand (COD), lipid accumulation, $\mathrm{pH}$ and concentration of coliforms. Lipid accumulation was measured by gravimetric analysis of the lipid fraction obtained after extraction from microalgae cells by organic solvents. During microalgae growth, in all experiments COD value decreased about three-fold. Average lipid content reached $30 \%$ of the cell weight and it was found that lipid accumulation depended on the cells' growth rate (Fig. 3), whereas the optimal cultivation cycle was found to be of about $24 \mathrm{~h}$. Potential energy of various fraction and products of algae grown in the Ariel West algal treatment stage were measured with Simultaneous Thermal Analysis device. It was found that the potential thermal energy of burning algae paste is somewhat like that of some alcohols $(\sim 1400 \mathrm{~J} / \mathrm{g})$, it was also found that burning the algae paste wet or dry is about the same and is higher than of the algae oil product.

In a $\mathrm{CO}_{2}$ absorption experiment two sealed monitoring ports were prepared near the gas inlet and outlet of the Ariel West greenhouse. The optimal algae beds angle was found to be about $80^{\circ}$, which created a series of $\mathrm{CO}_{2}$ assimilating layers. The parameters measured during the experiment's included $\mathrm{pH}$ and oxygen in the aquatic phase 
and oxygen and carbon dioxide (Vernier $\mathrm{CO}_{2}$ gas sensor, in ppm) concentrations in the greenhouse gas phase (Fig. 4). After validation of the monitoring equipment for atmospheric conditions the greenhouse natural steady state was measured and the flue gas flow was started at a rate of about $1.1 \mathrm{~m}^{3} / \mathrm{min}$ (Volvo FL $6121998132 \mathrm{~kW}$ engine). The $\mathrm{CO}_{2}$ concentration at the inlet was about $9700 \mathrm{ppm}$ and at the greenhouse outlet it dropped to about $2400 \mathrm{ppm}$. The current experiment is an upscale of at least two orders of magnitude compared to previous works [17-19]. The assimilation rate comparison suggests that the current configuration is much more efficient than those inspected at previous works, owing to the much larger effective surface area of the algae beds in the PBR.

\section{Conclusions}

Global reduction in fossil energy supply due to continuing over-consumption and negative environmental effects, poses a global infrastructural challenge at present and probably also in future. The most common sources for bioethanol today are sugar-rich feedstocks, including sugarcane, sugar beet and various fruits, which are converted into ethanol with a relatively high yield. Biodiesel is derived mainly from oil crops including soybean and oilseed rape. Unlike terrestrial biomass, aquatic biomass in form of micro and macro algae and also water plants are very promising renewable energy resources. Aquatic biomass is growing on and in various water bodies, without competing with most grains and vegetables for arable land and resources. In addition, the algal stage once applied for WW polishing and disinfection allows continuous biomass harvesting in large volumes. The present study suggests that algae concentration in a Bio-IPPC system reaches up to $3 \%$ of the reactor's volume, as such a small (a flow rate of about 200 cubic meters per day) WWTP could generate industrial amount of algal biomass that can be utilized for biofuels production and for more profitable raw materials.

In summary:

- Bio-IPPC may be utilized for the prevention of natural water resources deterioration owing to recharge with low grade WW;

- application of such systems for and by rural communities, can improve water availability for agriculture, also improving the regional water and energy budgets;

- Bio-IPPC system can be regarded as BAT to almost all industrial and domestic WW;

- although biomass generated energy is usually not the most nominal choice for biomass utilization, it is sufficient to supply the energy needs of the WWTP;

- utilization of the biomass to products with better cost efficiency than biofuels, may generate substantial source of income to the WWTP operator.

\section{Implications and influences}

This paper is defining a new term and methodology for integrative biological remediation of industrial effluents in both aquatic and gas phases. This holistic approach ensures an optimal cost efficient treatment to vast range of industrial and domestic pollutants with the transformation of the excessive biomass into a commercial raw material. These raw materials may be converted into bio-fuels through initiative mechanochemical process or to more profitable commodities.

We would like to remark that the Ariel West project was supported by the Israeli water authority, through the Water Associations R\&D fund and to thank the programs supervisors Dr. Giora Alon and Hezi Bilik. The project was supervised by the Yuvalim water association LTD and to thank its managers Yigal Rosenthal and Gabi Aberjil. The present research and project are funded and supervised by the Israel Electricity Company, Technical R\&D promotion program and we wish to thank Dr. Adrian Bianu and Arie Levinson for their constant support.

\section{References}

1. R.W. Bentley, Global oil and gas depletion: an overview, Energy Policy 30, 189 (2002)

2. A.J. Cavallo, Predicting the peak in world oil production, Nat. Resour. Res. 11, 187 (2002)

3. D. Helm, The future of fossil fuels - is it the end? OXREP 18, $24(2016)$

4. D.J. Griggs, M.S. Stafford, O. Gaffney, I. Noble, Sustainable development goals for people and planet, Nature 495, 305 (2013)

5. P. Capros, A. De-Vita, N. Tasios, P. Siskos, M. Kannavou, A. Petropoulos, S. Evangelopulou, M. Zampara, D. Papadopoulos, C. Nakos, L. Paroussos, K. Fragiadakis, S. Tsani, P. Karkatsoulis, N. Pragkos, N. Kouvaritakis, L. HoeglundIsaksson, W. Winiwarter, P. Purohit, A. Gomez-Sanabria, S. Frank, N. Forsell, M. Gusti, P. Havlik, M. Obersteiner, H. Witzke, M. Kestig, EU Reference Scenario 2016, Energy, $\mathbf{Q 2}$ Transport and GHG Emissions. Trends to 2050 (Office of the European Union, Luxembourg, 2016)

6. L. Brennan, P. Owende, Biofuels from microalgae - a review of technologies for production, processing, and extractions of biofuels and co-products, Renew. Sustain. Energy Rev. 14, 557 (2010)

7. G. Rasul, B. Sharma, The nexus approach to water-energyfood security: an option for adaptation to climate change, Clim. Policy 16, 682 (2016)

8. EUP, Concerning Integrated Pollution Prevention and ${ }_{\mathrm{Q} 3}$ Control (EU, Strasbourg, 2008)

9. USA EPA, Protection of the Environment Act 2003. P. 23 (2003)

10. EUP, Establishing Best Available Techniques (BAT) Conclusions, Under Directive 2010/75/EU of the European Parliament and of the Council on Industrial Emissions, for the Refining of Mineral Oil and Gas (2014)

11. A.M. Åkerström, L.M. Mortensen, B. Rusten, H.R. Gislerød, Biomass production and removal of ammonium and phosphate by Chlorella sp. in sludge liquor at natural light and different levels of temperature control, Springerplus 5, 676 (2016)

12. EU, Report on the Functioning of the European Carbon Market (2017), p. 34

13. Y. Anker, E. Katz, D. Mualem, Method and Device Suitable for Growing Algae, US 14/438, 657, IL 238696, IN 4814/ DELNP/2015, CH 201380069671.7, EU 12859300.1 (2012) 
14. Y. Anker, E. Katz, Aqueous Waste Treatment Method and Device, US 14/115, 355, IL 229191, EU 12726855.5 (2011)

15. Y. Anker, F. Nakonechny, B. Niazov, S. Lugovskoy, M. Nisnevitch, Biofuel production by fermentation of water plants and agricultural lignocellulosic by-products, in ICSREE 2016 (2016)

16. E. Gana, Development of Microalgae PBR Operational Array for Biodiesel Manufacturing. MSc. Thesis (Ariel University, Ariel, Israel, 2013) [in Heb.]

17. N.D. Lloyd, D.T. Canvin, D.A. Culver, Photosynthesis and photorespiration in algae, Plant Physiol. 59, 936 (1977)
18. S. Chinnasamy, A. Bhatnagar, R. Claxton, K.C. Das, Biomass and bioenergy production potential of microalgae consortium in open and closed bioreactors using untreated carpet industry effluent as growth medium, Bioresour. Technol. 101, 6751 (2010)

19. S.-Y. Chiu, C.-Y. Kao, T.-T. Huang, C.-J. Lin, S.-C. Ong, C.-D. Chen, J.-S. Chang, C.-S. Lin, Microalgal biomass production and on-site bioremediation of carbon dioxide, nitrogen oxide and sulfur dioxide from flue gas using Chlorella sp. cultures, Bioresour. Technol. 102, 9135 (2011)

Cite this article as: Yaakov Anker, David Mualem, Hagai Langstadter, Faina Nakonechny, Marina Nisnevitch, Integrative approach for wastewater treatment facilities with biomass transformation into energy, Renew. Energy Environ. Sustain. 2, 6 (2017) 